\section{Review Article}

Dement Geriatr Cogn Disord Extra 2021;11:26-28

DOI: 10.1159/000514181
Received: December 29, 2020

Accepted: December 29, 2020

Published online: February 16, 2021

\title{
COVID-19 Has Made the Elderly Lonelier
}

\author{
Mahdi Naeim ${ }^{a} \quad$ Ali Rezaeisharif $^{b} \quad$ Aziz Kamran $^{a}$ \\ ${ }^{a}$ Social Determinants of Health Research Center, Ardabil University of Medical Sciences, Ardabil, Iran; ${ }^{\mathrm{b}}$ Department \\ of Counseling, University of Mohaghegh Ardebili, Ardabil, Iran
}

\section{Keywords}

COVID-19 · Elderly · Aging

\begin{abstract}
Loneliness is a major risk factor for the elderly and can double their problems. When COVID-19 started, things became more difficult for the elderly. The news that the elderly are at a higher risk for severe COVID-19 than others made the elderly lonelier. This is a library type study that was conducted over 2 months using valid scientific sources and books. Based on the findings of this study, we believe that focusing on education and reminding people of the necessary dos and don'ts of illness, modifying their diet, emphasizing masking, and even familiarizing the elderly with social media and virtual activities will prevent them from suffering loneliness.

(C) 2021 The Author(s)

Published by S. Karger AG, Basel
\end{abstract}

Loneliness is a major risk factor for the elderly and can double their problems. When COVID-19 started, things became more difficult for the elderly. The news that the elderly are at a higher risk for severe COVID-19 than others made the elderly lonelier [1].

Jalil is immersed in loneliness. Most of the time he is alone, and the TV that now shows colored lines is on the verge of burning out. He was married for 12 years, and

karger@karger.com www.karger.com/dee

Karger"

BOPEN ACCESS
(C) 2021 The Author(s)

Published by S. Karger AG, Basel

This article is licensed under the Creative Commons AttributionNonCommercial-NoDerivatives 4.0 International License (CC BYNC-ND) (http://www.karger.com/Services/OpenAccessLicense) Usage and distribution for commercial purposes as well as any distribution of modified material requires written permission. when his wife died his lifestyle became lonely. Now, with the advent of COVID-19 and home quarantine, he is even lonelier. He is over 70 years old, and unemployment and loneliness have made him more tired. After retiring, he started a business with 1 or 2 of his friends. However, as a result of COVID-19 he has been confined to his house again. He feels useless and impatient. He no longer likes television and only listens constantly to the radio. He does not talk to anyone these days and that is what makes him depressed [2].

The quarantine has made 64-year-old Karim obsessive, and fear has become a major part of his life. He sleeps thanks to a pill but still wakes up several times a night due to stress and tension. He was not like that at all before, but these days the fear of getting COVID-19 and dying fills his mind. Fear took over his existence after he heard the news that one of his relatives died alone $[1,2]$.

\section{Severe Mental Conditions in the Elderly}

Many elderly people, in addition to being alone, do not have enough knowledge of the virtual world and cannot enjoy the benefits of cyberspace $[2,3]$.

The lack of a proper infrastructure for the elderly is a major problem. It is necessary to establish the necessary infrastructure to increase the participation of the elderly after the COVID-19 crisis. Due to the lack of infrastruc- 
ture, as well as the limited knowledge of the elderly regarding new technologies, it is expected that TV, radio, and volunteer groups will help fill the gap created for the elderly in this critical situation. Even frequent contact with loved ones can help reduce stress and anxiety in the elderly. However, the need for a comprehensive aging system, i.e., one that addresses loneliness, illness, and lifestyle, is being felt now more than ever $[1,4]$.

\section{Increasing the Vulnerability of the Elderly}

The elderly have always been vulnerable, and now their vulnerability has doubled. This situation has become even more poignant as statistics show that most of the dead were in their 50 s or older. For those who survive the virus, depression is exacerbated by isolation.

Loneliness is a major risk factor for the elderly and can double their problems. Depression, digestive problems, sleep disorders, and a fear of loneliness for the rest of their life are some of the issues that plague them. Video calls are one way to help ease this crisis, but these cannot reduce the problem of the elderly or fill the void of their loved ones $[2,4]$.

\section{Unnecessary Compassion Can Be Dangerous}

Sometimes children visit their parents out of compassion and hug them, thinking that because they show no symptoms they do not have COVID-19. Meanwhile, the insidious virus may remain asymptomatic; if it is transmitted to the elderly, it is not clear how it will appear and therefore the only way to avoid COVID-19 in the elderly is to prevent it [1].

\section{Take Abnormal Symptoms Seriously in the Elderly}

Any abnormal symptoms in the elderly should be taken seriously, as COVID-19 has a variety of symptoms. Heart, gastrointestinal, and respiratory problems are some of the symptoms of COVID-19, but the point is that the symptoms of the disease in the elderly are elliptical. Sometimes the disease occurs in them only with drowsiness. We always advise taking any change in the elderly seriously, because the slightest change can signify the onset of COVID-19. An elderly person in stable condition who suddenly has a change in condition should see a doctor immediately.

Naeim et al.: COVID-19 Has Made the Elderly Lonelier
The elderly should avoid public places as much as possible. Older people are more sensitive than other members of society so, although everyone in the community is advised to wear regular masks, older people should use more special masks such as medical masks. They should wash their hands regularly and, as the skin of the elderly may be more prone to dryness, they should use lotion regularly. In public places, the mask should be changed after $4 \mathrm{~h}$, and it is better to take a shower after each entry to the home $[2,5]$.

\section{The Elderly Have Become Lonelier}

The COVID-19 outbreak has led to increased stress and anxiety in the elderly, and missing their loved ones can be a difficult experience for them. At the same time, they should be motivated and aided by telephone counseling. The elderly need to find hope and motivation in the thought that the Covid-19 era will come to an end and they can return to their normal activities after quarantine. Quarantine stress, the lack of small daily activities, fear of getting infected, and reduced traffic are the types of stresses that affect the elderly. Although some older people experienced loneliness before the COVID-19 outbreak, aside from the quarantine and the threat to their health, the stress of loneliness is doubled for them, and this stress poses a danger to their physical health over time. Undoubtedly, prolonged stress weakens the immune system of the elderly and, in addition to being prone to COVID-19 disease, they also have diseases with infectious backgrounds that threaten their health $[1,6]$.

\section{Quarantine Increases Mental Disorders}

Quarantine can lead to mental disorders. Even the healthiest people, even the young, have mental problems during this period, and the effects can be seen only after COVID-19 is over. Elderly people, even under normal circumstances, need special psychological care. Today, with the outbreak of COVID-19 and due to the ambiguity of the dimensions of this disease and the biological characteristics of old age, more damage is lurking in front of them [6].

\section{Adapting to the Situation Is Difficult for the Elderly}

Reduced face-to-face visits and intensified social distancing cause psychological stress. Adaptation to new circumstances is usually difficult in old age; the elderly are

Dement Geriatr Cogn Disord Extra 2021;11:26-28 27 
generally dependent on others. Some are even dependent on others to meet their basic health needs [1].

We believe that focusing on education, and reminding people of the necessary dos and don'ts of illness, modifying their diet, emphasizing masking, and even familiarizing the elderly with social media and virtual activities, will prevent them from being overcome by loneliness.

\section{Acknowledgement}

Not applicable.

\section{Conflict of Interest Statement}

None of the authors have any conflict of interests to disclose.

\section{Funding Sources}

Not applicable.

\section{Author Contributions}

All of the authors contributed to the study conception and design. Material preparation, data collection, and analysis were performed by Ali Rezaeisharif, Mahdi Naeim, and Aziz Kamran. The first draft and revision of this paper were written by Mahdi Naeim, and all of the authors commented on this paper. All of the authors read and approved the final version of this work.

\section{References}

1 Armitage R, Nellums LB. COVID-19 and the consequences of isolating the elderly. Lancet Public Health. 2020 May;5(5):e256.

2 Briguglio M, Giorgino R, Dell'Osso B, Cesari $\mathrm{M}$, Porta M, Lattanzio F, et al. Consequences for the elderly after COVID-19 isolation: FEaR (frail elderly amid restrictions). Front Psychol. 2020 Sep;11:565052.
3 Kamran A, Naeim M. Behavioural change theories: a necessity for managing COVID-19. Public Health. 2020 Oct 20;S00333506(20)30452-2.

4 Naeim M. Coronavirus disease (COVID-19) outbreak provides a unique platform to review behavioral changes in Iran. Asian J Psychiatr. 2020 Jun;51:102090.
5 Kamran A, Naeim M, Rezaeisharif A. The COVID-19 outbreak and behavioral changes, public perceptions and psychological responses in Iran. Arch Psychiatr Nurs. 2020 Dec;34(6):458.

6 Petretto DR, Pili R. Ageing and COVID-19: what is the role for elderly people? Geriatrics (Basel). 2020 Apr;5(2):E25. 